\title{
- Local earthquake tomography with the inclusion of full = topography and its application to Kllauea volcano, s Hawai'i
}

Peng $\operatorname{Li}^{1}$ and Guoqing $\operatorname{Lin}^{1}$

Corresponding author: P. Li, Rosenstiel School of Marine and Atmospheric Science, University of Miami, Miami, FL 33149, USA. (pli@rsmas.miami.edu)

${ }^{1}$ Department of Marine Geosciences,

Rosenstiel School of Marine and

Atmospheric Science, University of Miami,

Miami, FL, 33149, USA. 
${ }_{4}$ Abstract. We develop a new three-dimensional local earthquake tomog-

s raphy algorithm with the inclusion of full topography (LETFT). We present

- both synthetic and real data tests based on the P- and S-wave arrival time

7 data for Klauea volcano in Hawai'i. A total of 33,768 events with 515,711

s P-picks and 272,217 S-picks recorded by 35 stations at the Hawaiian Volcano

- Observatory are used in these tests. The comparison between the new and

10

11 
${ }_{27}$ synthetic and real data tests and we expect that it will reveal more robust

${ }_{28}$ velocity structures in areas with larger topographic variations. 


\section{Introduction}

29 Local earthquake tomography (LET) refers to seismic tomography using local earth-

30

quake data. It has been widely used to solve for velocity structure of the Earth's crust and uppermost mantle in local or regional scales (from tens to hundreds of kilometers) [e.g., Aki et al., 1977; Thurber, 1984; Eberhart-Phillips, 1990; Rowan and Clayton, 1993; Zhang and Thurber, 2003; Lin et al., 2007; Park et al., 2009]. Because earthquake location and origin time are coupled with velocity structure, these parameters are often solved simultaneously. In seismic tomography, a study area is usually discretized by a series of cuboids without considering topography and the velocity structure is represented by the cuboids with constant velocity (Blocks method) [e.g., Aki et al., 1977; Humphreys and Clayton, 1988; Benz et al., 1992; Boschi and Dziewonski, 1999; Li et al., 2008; Zhao et al., 2013] or the vertices of cuboids (Nodes method) [e.g., Thurber, 1983; EberhartPhillips, 1986; Zhao and Kanamori, 1992; Steck et al., 1998; Syracuse et al., 2010; Lin, 2015]. If nodes method is used, interpolation of velocity at the nodes is needed to obtain the velocity structure of the whole study area. However, during the tomographic inversions in local scale, the neglect of topography may introduce errors in ray tracing and construction of tomographic equations, especially in areas with large topographic variations, such as volcanic or mountain areas. To reduce the effect of topography, traditional LET methods usually add extra layers above the surface and include station elevations in ray tracing [e.g., Thurber, 1992; Evans et al., 1994; Benz et al., 1996; Gentile et al., 2000; Karastathis et al., 2011]. However, this approximation can be problematic sometimes as 
49

\section{Methodology}

62 
71

72

73

74

75

76

grid spacing in typical LET. In the tomographic process, velocity model and earthquake source parameters (i.e., location and origin time) are solved iteratively by three steps, including forward, parameter separation and inverse parts. In the forward part, ray paths, arrival time residuals and partial derivative matrix of the velocity model and earthquake source parameters are calculated based on the initial velocity model or the velocity model from a previous iteration. We then separate the source and velocity parameters by using the method presented by Pavlis and Booker [1980]. In the inverse part, the velocity model and source parameters are updated based on the partial derivative matrix and arrival time residuals obtained from the forward part. The updated velocity model and source parameters are used for the next iteration. The iteration stops until the variation of the root-mean-square (RMS) of the arrival time residuals between the current and its previous iteration is smaller than a given threshold.

Figure 2 schematically illustrates the difference between the traditional LET method that includes station elevations and the new LETFT method. In the traditional LET method (Figure 2a), the whole study area is represented in a Cartesian coordinate system with a flat top and extra layers added above mean sea level (MSL) to include seismic stations into the study area, since they usually have certain elevations above MSL. The study area is then discretized into a series of nodes to represent the velocity model. The velocities of the nodes above the surface are also updated in the tomographic processing and affect the velocity both above and below the surface through interpolation, which is unrealistic for seismic P- and S-waves. Consequently, the ray paths are affected by the problematic velocity below and above the Earth's surface. In some cases, the rays could 
93

94

95

even travel above the surface. This problematic ray tracing could introduce errors in the velocity model and earthquake source parameters in the topographic processing.

In the new LETFT method (Figure 2b), we avoid using the velocity nodes above the Earth's surface and the unrealistic ray paths by including the full topography. The method is implemented by the following settings. First, we extend the upper boundary of the study area to a level slightly above the highest elevation in the study area. Second, we insert the topography data into the 3-D space of the study area. We then set the velocity in the volume above the surface to a small constant number (e.g., $0.34 \mathrm{~km} / \mathrm{s}$ or $1.5 \mathrm{~km} / \mathrm{s}$ for $\mathrm{P}$ velocity in air or water), which does not vary during the tomography inversion. In this study, we choose the constant velocity above the Earth's surface as $1.5 \mathrm{~km} / \mathrm{s}$. The velocities below the Earth's surface are set to an initial one or three-dimensional velocity model in the first iteration or an updated velocity model from a previous iteration. The model is set this way to simulate the real circumstances in the study area and reduce the errors in predicting ray paths and partial derivative matrix in the forward part of tomography. Third, the study area is parameterized by a set of cuboidal vertices which are separated as two sets by the topography. Nodes above the Earth's surface are not used in either the forward or the inverse part, which means that they are not used in the interpolation of the velocities below the Earth's surface in either the forward or the inverse part. Thus, the velocity nodes above the surface have no influence on the tomographic process. The velocity of the nodes below the surface is updated in each iteration of the inverse part and used to interpolate the updated velocity model of the study area.

In the forward part of the new LETFT algorithm, we use the Fast Marching Method, which is a finite difference method used to solve the Eikonal equation [Sethian and 
116

Popovici, 1999], to predict the ray paths, arrival time residuals and partial derivative matrix of the velocity model and earthquake source parameters. This method has been widely used in seismic tomography for its high stability and accuracy [e.g., Rawlinson and Sambridge, 2004; Li and Lin, 2014]. With the above settings of the inclusion of full topography, ray paths avoid the influence of velocity above the surface of the Earth and thus the accuracy of the partial derivative matrix and arrival time prediction are improved. After the forward process, the parameters of the velocity model and earthquake source are separated by the QR decomposition [Thurber, 1992] and updated subsequently. Velocity model is solved first by a damped least square method to minimize the following misfit function $\Phi[$ Tarantola, 2005],

$$
\begin{gathered}
\Phi(\boldsymbol{m})=\left\|\left(\boldsymbol{G} \boldsymbol{m}-\boldsymbol{d}_{\text {obs }}\right)\right\|^{2}+\left\|\boldsymbol{\lambda}\left(\boldsymbol{m}-\boldsymbol{m}_{\text {prior }}\right)\right\|^{2} \\
\boldsymbol{\lambda}=\left[\begin{array}{cc}
\boldsymbol{\lambda}_{\boldsymbol{p}} & 0 \\
0 & \boldsymbol{\lambda}_{\boldsymbol{s}}
\end{array}\right]
\end{gathered}
$$

where $\boldsymbol{G}$ is the separated partial derivative matrix of the velocity model, $\boldsymbol{m}$ is the model vector, $\boldsymbol{d}_{o b s}$ is the data vector, $\boldsymbol{m}_{\text {prior }}$ is a priori model, and $\boldsymbol{\lambda}$ is the damping parameter matrix. Because the ray coverages of $\mathrm{P}$ - and S-waves are different, we use different damping parameters for $\mathrm{P}$ - and S-waves as $\lambda_{p}$ and $\lambda_{s}$, which are the diagonal elements of $\boldsymbol{\lambda}_{\boldsymbol{p}}$ and $\boldsymbol{\lambda}_{\boldsymbol{s}}$, respectively. After getting the velocity of the inversion nodes, we use a trilinear interpolation to obtain the velocity model in the study area beneath the surface, which only includes the nodes below the Earth's surface. The earthquake locations are then solved based on the new velocity model by using the singular value decomposition method [Golub and Reinsch, 1970]. 


\section{Data Set}

We choose Knlauea volcano in Hawai'i (Figure 3) to test our method and algorithm because it is one of the most seismically active areas in the world with a fair amount of topographic relief ( $\sim 1 \mathrm{~km}$ above MSL). Another advantage of Kllauea volcano is the numerous velocity models from previous tomographic studies to compare with our results. The data used in this study are the 515,711 P- and 272,217 S-wave arrival times of 33,768 seismic events between 1992 and 2009 recorded by 35 seismic stations at the HVO. We select the events with the greatest number of picks within $2 \times 2 \times 2 \mathrm{~km}^{3}$ cubes as the master events for the inversion. After this data processing, we obtain 1,800 master events with 30,172 P-picks and 12,673 S-picks as the inputs for our study, with $17 \mathrm{P}$ and $7 \mathrm{~S}$ per event on average.

\section{Synthetic Data Test}

The synthetic P- and S-wave velocity models in our test are obtained by perturbing a one-dimensional (1-D) velocity model with checkerboard-shape anomalies. The 1-D models are obtained by calculating the layer-average values of the 3 -D velocity model from Lin et al. [2014] and are also used as the initial models for both the synthetic and the real data inversions. The amplitudes of the anomalies are $\pm 10 \%$ of the $1-\mathrm{D}$ P- and S-wave velocity model, respectively. The study area is parameterized by a series of cuboidshaped grid nodes. The horizontal grid spacing of our model is $3 \mathrm{~km}$. In vertical, the spacing is $3 \mathrm{~km}$ above and $5 \mathrm{~km}$ below $11 \mathrm{~km}$ depth. The total number of unknowns in the inversion is 13,728 (about one third of the input), including 3,264 P-wave velocity nodes, 3,264 S-wave velocity nodes and 7,200 hypocentral parameters. The arrival times are calculated based on the synthetic velocity model with the station, earthquake and 
156

ray distributions from the real data processing. We also add Gaussian-distributed noise with zero mean and $1 \mathrm{~km}$ standard deviation (STD) to the earthquake locations and $0.1 \mathrm{~s}$ standard deviation to the origin times, which are used as the initial values for the simultaneous P and S-wave velocity and source parameter inversions.

Before the final tomographic process, we tested a series of damping parameters ranging from 10 to 25,000 in order to find the optimal damping parameters $\left(\lambda_{p}\right.$ and $\lambda_{s}$ in equation 1) for the inversion of P- and S-velocity models, separately. The strategy is similar to that described by Lin et al. [2007] and Lin et al. [2014]. First, we fix $\lambda_{s}$ at a number as large as 25,000 to find the optimal $\lambda_{p}$. The data misfit and model variance resulted from different damping parameters are calculated and plotted as the trade-off curve shown in Figure 4a. We normalized the data misfit and model variance, same as in Lin [2015], so that it is more straightforward to compare the relative scale of the $\mathrm{x}$ - and y-axes. We select 200 for the damping parameter $\lambda_{p}$, which provides an optimal compromise between data misfit and model variance. Second, we fix $\lambda_{p}$ as 200 and find the damping parameter $\lambda_{s}$. From the trade-off curve of $\lambda_{s}$ (Figure $4 \mathrm{~b}$ ), we select 150 as S-velocity damping parameter $\lambda_{s}$. We then fix $\lambda_{s}$ as 150 with a series of $\lambda_{p}$ and confirm that 200 is indeed the optimal $\lambda_{p}$ for P-velocity. After this step, we use damping parameters of 200 and 150 for the inversions of $\mathrm{P}$ - and S-wave velocity models in our final tomography.

The results of our synthetic data tests are shown in Figures 5 and 6 . Figure 5a and 6a present the 1-D initial reference P- and S-wave velocity models, respectively. Figure $5 \mathrm{~b}$ and $6 \mathrm{~b}$ show the synthetic P- and S-wave velocity models, respectively. We compare our new LETFT method and the traditional LET method with the inclusion of station elevations along a profile (A-A' in Figure 3a) across the study area from the west to 
the east side. Note that zero depth represents MSL and the depths in the following sections are all relative to MSL, instead of the ground surface. Figures 5c-d and 6c-d are the inverted P- and S-wave velocity models along profile A-A', respectively. The black contours enclose the areas with the diagonal elements of the resolution matrix greater than 0.4, where the velocity models are considered to be well-recovered. Note that the values of the resolution throughout the grid space could be increased by decreasing the damping parameter, but the velocity results may be less reliable. The new and the traditional methods have similar well-resolved area because the resolution matrix is calculated from the same initial velocity model and damping parameters. For the P-wave velocity model, the pattern of the velocity anomalies from the LETFT (Figure 5c) is much closer to the true model than that from the LET method (Figure 5d), especially at shallow layers (above $5 \mathrm{~km}$ depth). These features are more clear in Figures 5e and $\mathrm{f}$, which show the velocity difference between the inverted and the synthetic models. The S-wave velocity model from the LETFT method is much more similar to the true model than that from the traditional LET method (Figures 6c-d), although the well resolved area is smaller than the P-wave velocity model due to the much fewer S-picks and sparser ray coverage. The model difference also clearly shows this (Figures 6e-f). The model comparison shows that the new algorithm recovers the true model better than the traditional method, especially at shallow depths, which indicates that the neglect of full topography may cause significant bias of the shallow velocity structure estimation.

In Table 1, we show the quantitative comparison of the inversion results between the new LETFT and the traditional LET methods. Earthquake location and origin time errors are the mean values of the differences between the inverted and the true values 
from all the input master events. The location errors from the LETFT method are 49.9 $\mathrm{m}, 56.2 \mathrm{~m}$ and $75.7 \mathrm{~m}$ in longitude, latitude and depth, respectively, whereas the errors from the traditional LET method are $103.7 \mathrm{~m}, 110.7 \mathrm{~m}$ and $157.3 \mathrm{~m}$, which are about twice of those from the LETFT method. Similarly, the origin time error from the LETFT method $(0.018 \mathrm{~s})$ is also much smaller than that from the traditional LET method (0.052 s). The velocity model error is the average value of the differences between the inverted and the true velocities on the well-resolved inversion nodes whose diagonal elements of the resolution matrix are greater than 0.4 . The P-wave velocity errors of the LETFT and the traditional LET methods are $0.15 \mathrm{~km} / \mathrm{s}$ and $0.20 \mathrm{~km} / \mathrm{s}$, respectively. The most significant difference between the two methods occur at shallow depths. The velocity model errors for the well-resolved nodes above $5 \mathrm{~km}$ depth are $0.09 \mathrm{~km} / \mathrm{s}$ and $0.20 \mathrm{~km} / \mathrm{s}$ for the LETFT and the LET methods. The S-wave velocity errors of the LETFT and the traditional LET methods are $0.12 \mathrm{~km} / \mathrm{s}$ and $0.21 \mathrm{~km} / \mathrm{s}$, respectively. Above $5 \mathrm{~km}$ depth, the S-wave velocity error of the LETFT method is $0.09 \mathrm{~km} / \mathrm{s}$, which is much smaller than the error of $0.21 \mathrm{~km} / \mathrm{s}$ from the traditional LET method. The LETFT method reduces the velocity model errors by $25 \%$ and $42 \%$ for Vp and Vs models in the entire depth range and by $\sim 55 \%$ and $\sim 57 \%$ for $\mathrm{Vp}$ and $\mathrm{Vs}$ models above $5 \mathrm{~km}$ depth, respectively. We also calculate the root mean square of the arrival time residuals from each method, which is $0.013 \mathrm{~s}$ for the LETFT method and $0.016 \mathrm{~s}$ for the traditional LET method. These quantitative comparisons between the two methods show that the LETFT method fits the data better and results smaller errors in both the velocity model and source parameters. 


\section{Application to Kllauea Volcano}

\subsection{Model Results}

In the real data test, the velocity model is represented by a set of cuboidal nodes with $3 \mathrm{~km}$ horizontal spacing. The vertical interval is $3 \mathrm{~km}$ above and $5 \mathrm{~km}$ below 11 $\mathrm{km}$ depth. The velocity of each node is updated in the inverse part of tomography and the velocity below the Earth's surface is determined by a trilinear interpolation of the nodes. The model is solved iteratively and the threshold (see Figure 1) of terminating the tomographic inversion is chosen as $1 \%$, which means that the reduction of the arrival time residual RMS is smaller than $1 \%$ of the RMS from the previous iteration. For Klauea, the LETFT program runs 16 iterations to reach this threshold and each iteration takes $\sim 55$ minutes on an Intel E5 cpu $(2.6 \mathrm{GHz})$. After we obtain the final P- and S-wave velocity models in Kllauea, the RMS of the total arrival time residuals is reduced from $0.65 \mathrm{~s}$ for the initial 1-D model to $0.14 \mathrm{~s}$ for the inverted 3-D model (Figure 7). The RMS of the P-wave arrival time residuals drops from $0.55 \mathrm{~s}$ to $0.12 \mathrm{~s}$ and the RMS of the S-wave residuals drops from $0.83 \mathrm{~s}$ to $0.16 \mathrm{~s}$.

Figures 8 and 9 show the well-resolved area of the final P- and S-wave velocity models along the profiles shown in Figure 3a. The model is considered well resolved where the diagonal element of the resolution matrix is greater than 0.4 , same as in the synthetic data test. The white crosses are the projections of the inversion nodes within $\pm 1.5 \mathrm{~km}$ distance of the profile line, which reflect the distribution of the inversion nodes. All the inversion nodes are below the ground surface. The black dots represent the relocated seismicity within $\pm 0.5 \mathrm{~km}$ distance of the profile lines from a recent location catalog by Lin et al. [2014]. Zero depth again represents MSL. 
244

Our new 3-D P- and S-wave velocity models reveal several interesting features. Figure 8 shows the P- and S-wave velocity models along four parallel profiles (1-1', 2-2', 3-3' and 4-4' in Figure 3a) that are perpendicular to the East Rift Zone (ERZ) and pass through K1lauea caldera and the Southwest Rift Zone (SWRZ). Profiles 1-1' is across the upper ERZ at Pu'u'O'ō crater. To the north of the upper ERZ along profile 1-1', there is a high P-wave velocity zone at $\sim 10 \mathrm{~km}$ depth (distance $=0-13 \mathrm{~km}$, Figure 8a). This feature is close to the edge of the good resolution contour and should be interpreted carefully. The Vp beneath Pu'u'O' $\overline{\mathrm{o}}$ (distance=15-16 km) is $\sim 5.5 \mathrm{~km} / \mathrm{s}$ (Figure 8a) at 6-10 km depth. The well resolved area along 1-1' is small and we can only see the S-wave velocity is about $3.5 \mathrm{~km} / \mathrm{s}$ at 5-8 km depth beneath Pu'u'O'ō (Figure 8e, distance $=15-16 \mathrm{~km}$ ). Profiles 2-2' is across the upper ERZ at Makaopuhi crater. High Vp zone is also observed to the north of ERZ (distance $=0-13 \mathrm{~km}$ ) with a velocity of $\sim 7.5 \mathrm{~km} / \mathrm{s}$ (Figure $8 \mathrm{~b}$ ). It expands to 5-9 km beneath Makaopuhi (distance=14-15 km) in the upper ERZ. The P-wave velocity beneath the Hilina fault system (HFS, distance $=21-22 \mathrm{~km}$ ) is about $5.3 \mathrm{~km} / \mathrm{s}$. Along 2-2' profile, Vs varies from $4.0 \mathrm{~km} / \mathrm{s}$ in the north (distance $=0-11 \mathrm{~km}$ ) to $3.5 \mathrm{~km} / \mathrm{s}$ beneath Makaopuhi (distance=14-15 km, Figure 8f). Profile 3-3' passes through Kllauea caldera and the Koa'e fault system (KFS, distance=13-14 km). In Figure 8c and g, high Vp $(\sim 7.4 \mathrm{~km} / \mathrm{s})$ and $\mathrm{Vs}(\sim 4.1 \mathrm{~km} / \mathrm{s})$ dominate the depth between $5 \mathrm{~km}$ and $11 \mathrm{~km}$ beneath K1lauea caldera. Beneath the KFS, Vp and Vs decrease to about $6.1 \mathrm{~km} / \mathrm{s}$ and $3.6 \mathrm{~km} / \mathrm{s}$, respectively. The most significant feature along profile 4-4' that is across the SWRZ is a high Vp zone at $5-9 \mathrm{~km}$ depth with a velocity of $\sim 7.4 \mathrm{~km} / \mathrm{s}$ (distance $=7-8 \mathrm{~km}$, Figure $8 \mathrm{~d}$ ). However, Vs is about $3.6 \mathrm{~km} / \mathrm{s}$ in this area (Figure $8 \mathrm{~h}$ ), which is not significantly higher than the surrounding area. 
residuals (Figure 7) of the real $\mathrm{P}$ - and S-wave velocity model inversion are used as the mean and STD of the Gaussian noise. The arrival time residual of the inverted velocity model usually consists of errors caused by both model errors and random noise and could be larger or at the same level as the noise of data. In this study, we add Gaussian distributed noise with $0.002 \mathrm{~s}$ mean and $0.12 \mathrm{~s}$ STD to the P-wave arrival time data, and $0.002 \mathrm{~s}$ and $0.16 \mathrm{~s}$ STD to S-wave arrivals, respectively. The P- and S-wave velocity models are inverted with the noise perturbed data. Figure 10 shows the results of the well resolved area from the perturbed data along profile A-A' in Figure 3a. In the Vp models from the original and perturbed data along profile A-A' (Figure 9a and 10a), the high and low P-wave velocity features are very similar, except at the boundary of the well resolved area (distance $=5-10 \mathrm{~km}$ ). The S-wave velocity from the original data (Figure 9d) and perturbed data (Figure 10b) are also similar to each other, although the velocity at $\sim 8$ $\mathrm{km}$ depth with a distance of $\sim 31.5 \mathrm{~km}$ in Figure 10b is slightly overestimated than that in Figure 9d. The result of the robustness test indicates that our P- and S-wave velocity models are reliable with respect to noise.

\subsection{Comparison With LET Results}

Similar to the synthetic data test, we compare the velocity models resulting from the LETFT and the traditional LET methods based on the real data set in Klanea. Figure 11 shows the Vp and Vs models from the two approaches along the vertical profile B-B'B". We find the improvements of the LETFT method in the real data test are mainly at shallow depths and a few additional ones in the deep layers, similar to the areas of the improvements in the synthetic test. Figure $11 \mathrm{a}$ and $\mathrm{b}$ are the P-wave velocity models from the LETFT and the traditional LET method, respectively. The most significant 
311

improvement is the velocity below Kilauea caldera at 0-3 km depth (5-12 km distance).

Klauea caldera is a vigorous area and is unlikely to have the smooth layered velocity model at shallow depths as shown in the result of the traditional LET method. In contrast, the LETFT resolves more detailed velocity structures below Kllauea caldera. There are also a few subtle differences at 2-7 km depth (15-20 km distance). Figures $11 \mathrm{c}$ and $\mathrm{d}$ are the S-wave velocity models from the LETFT and the traditional LET method, respectively. The major improvements exist in two areas. One is at 0-3 km depth below Kllauea caldera (5-12 $\mathrm{km}$ distance), and the other is around $5 \mathrm{~km}$ depth (10-15 km distance). Owing to the same event, station, and ray distributions used in the synthetic test, our real data inversion should have the similar capability of recovering the true velocity model. Our results show that the synthetic and real data tests are consistent and the improvements in the real data test are believable.

\section{Discussion}

In traditional body wave LET methods, topography is usually neglected and sometimes only station elevations are included to approximate the effect of topography. This approximation may introduce errors to the prediction of arrival times and partial derivative matrix of source and velocity parameters in the forward part of tomography. It could also bring errors to the velocity model in the inverse part of tomography. The amplitude of the errors depends on the variations of local topography. In our new LETFT algorithm, this kind of systematic error is avoided by including the full topography in both the forward and inverse parts of tomography and only updating the velocity below the Earth's surface. The synthetic data test shows that the new LETFT method is able to recover the true velocity better in both shallow and deep parts of the crust compared to the traditional 
LET method. The calculated errors in the inverted velocity model, earthquake locations and arrival time residuals also provide quantitative proof of the improvement of the new method over the traditional one.

In the real data application to Kllauea volcano, we observe several notable Vp and Vs structures. At Kllauea caldera, the $\mathrm{Vp}(\sim 3.9 \mathrm{~km} / \mathrm{s})$ and $\mathrm{Vs}(\sim 2.6 \mathrm{~km} / \mathrm{s})$ are higher than the surrounding area from the surface to $1 \mathrm{~km}$ depth below MSL, which are decreased to $3.7 \mathrm{~km} / \mathrm{s}$ and $2.3 \mathrm{~km} / \mathrm{s}$ at $2 \mathrm{~km}$ depth. The abundant seismicity indicates that this area is very active. This low Vp zone was also observed by Thurber [1984] and Rowan and Clayton [1993] and was interpreted as the locus of magma complex. However, low Vp can be caused by many factors, such as rock composition, fracture and fluid content [Lin, 2015]. Vs is more sensitive to shear modulus than Vp. Partial melt can decrease shear modulus, and thus Vp and Vs. Therefore, in addition to low Vp, the reduction in our Vs model at Kllauea caldera provides more evidence for the presence of magma. Below $2 \mathrm{~km}$ depth, there is a high Vp zone $(>7.0 \mathrm{~km} / \mathrm{s})$ at $5-14 \mathrm{~km}$ depth and high Vs zone $(>3.9 \mathrm{~km} / \mathrm{s})$ at $5-11 \mathrm{~km}$ depth. This high $\mathrm{Vp}$ zone was also observed in previous studies [Dawson et al., 1999; Monteiller et al., 2005; Park et al., 2009; Lin et al., 2014] and was interpreted as consolidated intrusive gabbro-ultramafic cumulates [Okubo et al., 1997; Haslinger et al., 2001]. The high Vs in this area also supports this interpretation.

To the north of the upper ERZ from Makaopuhi to Pu'u'O'’-̄, we observe high Vp $(>7.0 \mathrm{~km} / \mathrm{s})$ and $\mathrm{Vs}(>3.9 \mathrm{~km} / \mathrm{s})$ zone at $8-12 \mathrm{~km}$ depth. In the upper ERZ, there is also a high $\mathrm{Vp}(>7.0 \mathrm{~km} / \mathrm{s})$ zone at $5-9 \mathrm{~km}$ depth beneath Makaopuhi. These high Vp zones are consistent with the high Bouguer gravity anomaly in this area [Kinoshita, 1965; Kauahikaua, 1993], indicating dense intrusions with high velocity [Hill and Zucca, 1987; 
Kauahikaua, 1993]. In the ERZ, the high Vp zone is not continuous and we observe relatively low $\operatorname{Vp}(\sim 5.5 \mathrm{~km} / \mathrm{s})$ zone at 6-10 km depth beneath Pu'u'O'ō. This low Vp is similar to the velocity of olivine basalt or plagioclase basalt from the oceanic crust [Schreiber and Fox, 1977; Christensen, 1996]. The similar discontinuous high Vp (>7.0 $\mathrm{km} / \mathrm{s}$ ) zone is also found below $4 \mathrm{~km}$ depth in the SWRZ. The high Vp zone of 4-10 $\mathrm{km}$ depth at the bend of the SWRZ (around C' in Figure 3a) indicates a concentrated intrusion zone as a barrier to magma propagation [Klein et al., 1987]. Rowan and Clayton [1993] interpreted that this feature changed the direction of the SWRZ and local stresses.

In the HFS, there is a thin high Vp layer $(\sim 7.0 \mathrm{~km} / \mathrm{s})$ at $4-6 \mathrm{~km}$ depth and Vp decreases to as low as $\sim 5.7 \mathrm{~km} / \mathrm{s}$ at $6-11 \mathrm{~km}$ depth, which has a sharp contrast to the high Vp in the ERZ. The low Vp zone was also observed by Rowan and Clayton [1993] and Haslinger et al. [2001]. The Bouguer gravity anomaly in the HFS is smaller than that in the ERZ [Kinoshita, 1965; Kauahikaua, 1993], indicating relatively less dense materials in the subsurface of the HFS. With the evidence above, we suggest that the high Vp layer at 5-6 $\mathrm{km}$ is the intrusive ultramafic gabbro sills. The horizontal linear distribution of seismicity at $6 \mathrm{~km}$ depth supports our suggestion since the seismicity likely occurs at the fractures caused by intrusive ultramafic gabbro sills. To the south of the KFS, Vp is 6.1 $\mathrm{km} / \mathrm{s}$ and $\mathrm{Vs}$ is $\sim 3.5 \mathrm{~km} / \mathrm{s}$ at $5-9 \mathrm{~km}$ depth, in contrast to the high $\mathrm{Vp}(>7.0 \mathrm{~km} / \mathrm{s})$ and $\mathrm{Vs}$ $(>3.9 \mathrm{~km} / \mathrm{s})$ to the north of the KFS. This indicates that the intrusive activities mainly occur to the north of the KFS, given the Bouguer gravity anomaly contrast around the KFS [Kauahikaua, 1993]. 


\section{Conclusions}

In this paper, We develop and present a new local earthquake tomography algorithm with the inclusion of full topography (referred to as LETFT). The algorithm naturally avoids possible errors that may be caused by the neglect of local topography and improves the accuracy of the resulting velocity model, especially at shallow depths. The application of the new algorithm to Kllauea area, Hawai'i, reveals several notable Vp and Vs structures. The high Vp zone beneath Kllauea caldera agrees with the previous studies and indicates the consolidated intrusive gabbro-ultramafic cumulates. In our model, this high Vp zone extends to the north of the ERZ and shows discontinuity in the ERZ. We also find high Vp layer in the HFS and the velocity contrast between the north and south sides of the KFS. Considering the highest elevation of the Kllauea area is about $2 \mathrm{~km}$ above MSL, we expect that our algorithm will uncover more robust velocity structures in areas with larger topographic variations (e.g., Mauna Loa volcano with $4 \mathrm{~km}$ elevation near the summit). In the future, we will add direct inversion of $\mathrm{Vp} / \mathrm{Vs}$ and differential time data [Zhang and Thurber, 2003] in the LETFT, which could provide more information to understand the subsurface structures.

Acknowledgments. We thank the Hawaiian Volcano Observatory for maintaining the seismic network and Paul G. Okubo for making the data available and for the helpful discussions. We are grateful to Joachim Ritter and an anonymous reviewer for their constructive and detailed comments. Funding for this research was provided by the National Science Foundation grant EAR-1246935. Plots were made with GMT software [Wessel and Smith, 1991]. 


\section{References}

Aki, K., A. Christoffersson, and E. S. Husebye (1977), Determination of the threedimensional seismic structure of the lithosphere, J. Geophys. Res., 82(2), 277-296.

Benz, H., G. Zandt, and D. Oppenheimer (1992), Lithospheric structure of northern California from teleseismic images of the upper mantle, J. Geophys. Res., 97(B4), 47914807.

Benz, H., B. Chouet, P. Dawson, J. Lahr, R. Page, and J. Hole (1996), Three-dimensional P and S wave velocity structure of Redoubt Volcano, Alaska, J. Geophys. Res., 101 (B4), $8111-8128$.

Boschi, L., and A. M. Dziewonski (1999), High-and low-resolution images of the earth's mantle: Implications of different approaches to tomographic modeling, J. Geophys. Res., $104(\mathrm{~B} 11), 25,567-25,594$.

Christensen, N. I. (1996), Poisson's ratio and crustal seismology, J. Geophys. Res., $101(\mathrm{~B} 2), 3139-3156$.

Dawson, P., B. Chouet, P. Okubo, A. Villaseñor, and H. Benz (1999), Three-dimensional velocity structure of the Kilauea caldera, Hawaii, Geophys. Res. Lett., 26(18), 28052808.

Eberhart-Phillips, D. (1986), Three-dimensional velocity structure in northern California coast ranges from inversion of local earthquake arrival times, Bull. Seismol. Soc. Am., $76(4), 1025-1052$.

Eberhart-Phillips, D. (1990), Three-dimensional P and S velocity structure in the Coalinga region, California, J. Geophys. Res., 95 (B10), 15,343-15,363. 
419

Evans, J. R., D. Eberhart-Phillips, and C. Thurber (1994), User's manual for SIMULPS12 for imaging $\mathrm{Vp}$ and $\mathrm{Vp} / \mathrm{Vs}$ : A derivative of the "Thurber" tomographic inversion SIMUL3 for local earthquakes and explosions, Open-File Report 94-431, US Geological Survey.

Gentile, G., G. Bressan, L. Burlini, and R. De Franco (2000), Three-dimensional Vp and $\mathrm{Vp} / \mathrm{Vs}$ models of the upper crust in the Friuli area (northeastern Italy), Geophys. J. Int., $141(2), 457-478$.

Golub, G. H., and C. Reinsch (1970), Singular value decomposition and least squares solutions, Numerische mathematik, 14(5), 403-420.

Haslinger, F., C. Thurber, M. Mandernach, and P. Okubo (2001), Tomographic image of P-velocity structure beneath Kilauea's East Rift Zone and South Flank: Seismic evidence for a deep magma body, Geophys. Res. Lett., 28(2), 375-378.

Hill, D. P., and J. J. Zucca (1987), Geophysical constraints on the structure of Kilauea and Mauna Loa volcanoes and some implications for seismomagmatic processes, US Geol. Surv. Prof. Pap, 1350(903-917).

Humphreys, E., and R. W. Clayton (1988), Adaptation of back projection tomography to seismic travel time problems, J. Geophys. Res., 93(B2), 1073-1085.

Karastathis, V., J. Papoulia, B. Di Fiore, J. Makris, A. Tsambas, A. Stampolidis, and G. Papadopoulos (2011), Deep structure investigations of the geothermal field of the North European Gulf, Greece, using 3-D local earthquake tomography and Curie Point Depth analysis, J. Volcanol. Geotherm. Res., 206(3), 106-120.

Kauahikaua, J. (1993), Geophysical characteristics of the hydrothermal systems of Kilauea volcano, Hawaii, Geothermics, 22(4), 271-299. 
442

443

444

445

446

447

448

449

450

451

Kinoshita, W. (1965), A gravity survey of the island of Hawaii, Pac. Sci., 19(3), 349.

Klein, F., R. Koyanagi, J. Nakata, and W. Tanigawa (1987), The seismicity of Kilauea's magma system, US Geol. Surv. Prof. Pap, 1350, 1019-1185.

Li, C., R. D. van der Hilst, E. R. Engdahl, and S. Burdick (2008), A new global model for P wave speed variations in Earth's mantle, Geochem. Geophys. Geosyst., 9(5).

Li, P., and G. Lin (2014), Adaptive ambient noise tomography and its application to the Garlock fault, southern California, Geophys. J. Int., p. ggu073.

Lin, G. (2015), Seismic velocity structure and earthquake relocation for the magmatic system beneath Long Valley Caldera, eastern California, J. Volcanol. Geotherm. Res., 296, 19-30.

Lin, G., P. M. Shearer, E. Hauksson, and C. H. Thurber (2007), A three-dimensional crustal seismic velocity model for southern California from a composite event method, J. Geophys. Res., 112(B11), doi:10.1029/2007JB004977.

Lin, G., P. M. Shearer, R. S. Matoza, P. G. Okubo, and F. Amelung (2014), Threedimensional seismic velocity structure of Mauna Loa and Kilauea volcanoes in Hawaii from local seismic tomography, J. Geophys. Res., 119(5), 4377-4392.

Monteiller, V., J.-L. Got, J. Virieux, and P. Okubo (2005), An efficient algorithm for double-difference tomography and location in heterogeneous media, with an application to the Kilauea volcano, J. Geophys. Res., 110(B12).

Okubo, P. G., H. M. Benz, and B. A. Chouet (1997), Imaging the crustal magma sources beneath Mauna Loa and Kilauea volcanoes, Hawaii, Geology, 25(10), 867-870.

Park, J., J. K. Morgan, C. A. Zelt, and P. G. Okubo (2009), Volcano-tectonic implications of 3-D velocity structures derived from joint active and passive source tomography of 
${ }_{465}$ the island of Hawaii, J. Geophys. Res., 114(B9).

Pavlis, G. L., and J. R. Booker (1980), The mixed discrete-continuous inverse problem: Application to the simultaneous determination of earthquake hypocenters and velocity structure, J. Geophys. Res., 85(B9), 4801-4810.

Rawlinson, N., and M. Sambridge (2004), Multiple reflection and transmission phases in complex layered media using a multistage fast marching method, Geophysics, 69(5), $1338-1350$.

Rowan, L. R., and R. W. Clayton (1993), The three-dimensional structure of Kilauea volcano, Hawaii, from travel time tomography, J. Geophys. Res., 98(B3), 4355-4375.

Schreiber, E., and P. J. Fox (1977), Density and P-wave velocity of rocks from the FAMOUS region and their implication to the structure of the oceanic crust, Geol. Soc. Am. Bull., 88(4), 600-608.

Sethian, J. A., and A. M. Popovici (1999), 3-D traveltime computation using the fast marching method, Geophysics, 64(2), 516-523.

Steck, L. K., C. H. Thurber, M. C. Fehler, W. J. Lutter, P. M. Roberts, W. S. Baldridge, D. G. Stafford, and R. Sessions (1998), Crust and upper mantle P wave velocity structure beneath Valles caldera, New Mexico: Results from the Jemez teleseismic tomography experiment, J. Geophys. Res., $103(\mathrm{~B} 10)$, 24,301-24,320.

Syracuse, E. M., C. H. Thurber, C. J. Wolfe, P. G. Okubo, J. H. Foster, and B. A. Brooks (2010), High-resolution locations of triggered earthquakes and tomographic imaging of Kilauea Volcano's south flank, J. Geophys. Res., $115(\mathrm{~B} 10)$.

Tarantola, A. (2005), Inverse problem theory and methods for model parameter estimation, 57-80 pp., SIAM, Philadephia, PA. 
${ }_{488}$ Thurber, C. H. (1983), Earthquake locations and three-dimensional crustal structure in

489 the Coyote Lake area, central California, J. Geophys. Res, 88(B10), 8226-8236.

${ }_{490}$ Thurber, C. H. (1984), Seismic detection of the summit magma complex of Kilauea vol-

${ }_{491}$ cano, Hawaii, Science, 223(4632), 165-167.

${ }_{492}$ Thurber, C. H. (1992), Hypocenter-velocity structure coupling in local earthquake tomog${ }_{493}$ raphy, Phys. Earth. Planet. In., 75(1), 55-62.

${ }_{494}$ Wessel, P., and W. H. F. Smith (1991), Free software helps map and display data, Eos, ${ }_{495} \quad$ Trans. $A G U, 72(41), 441-446$.

${ }_{496}$ Zhang, H., and C. H. Thurber (2003), Double-difference tomography: The method and its ${ }_{497}$ application to the Hayward fault, California, Bull. Seismol. Soc. Am., 93(5), 1875-1889.

498 Zhao, D., and H. Kanamori (1992), P-wave image of the crust and uppermost mantle in 499 southern California, Geophys. Res. Lett., 19(23), 2329-2332.

soo Zhao, D., Y. Yamamoto, and T. Yanada (2013), Global mantle heterogeneity and its ${ }_{501}$ influence on teleseismic regional tomography, Gondwana Res., 23(2), 595-616.

${ }_{502}$ Zhu, H., and J. E. Ebel (1994), Tomographic inversion for the seismic velocity structure ${ }_{503}$ beneath northern New England using seismic refraction data, J. Geophys. Res., 99(B8), ${ }_{504} \quad 15,331-15,357$. 


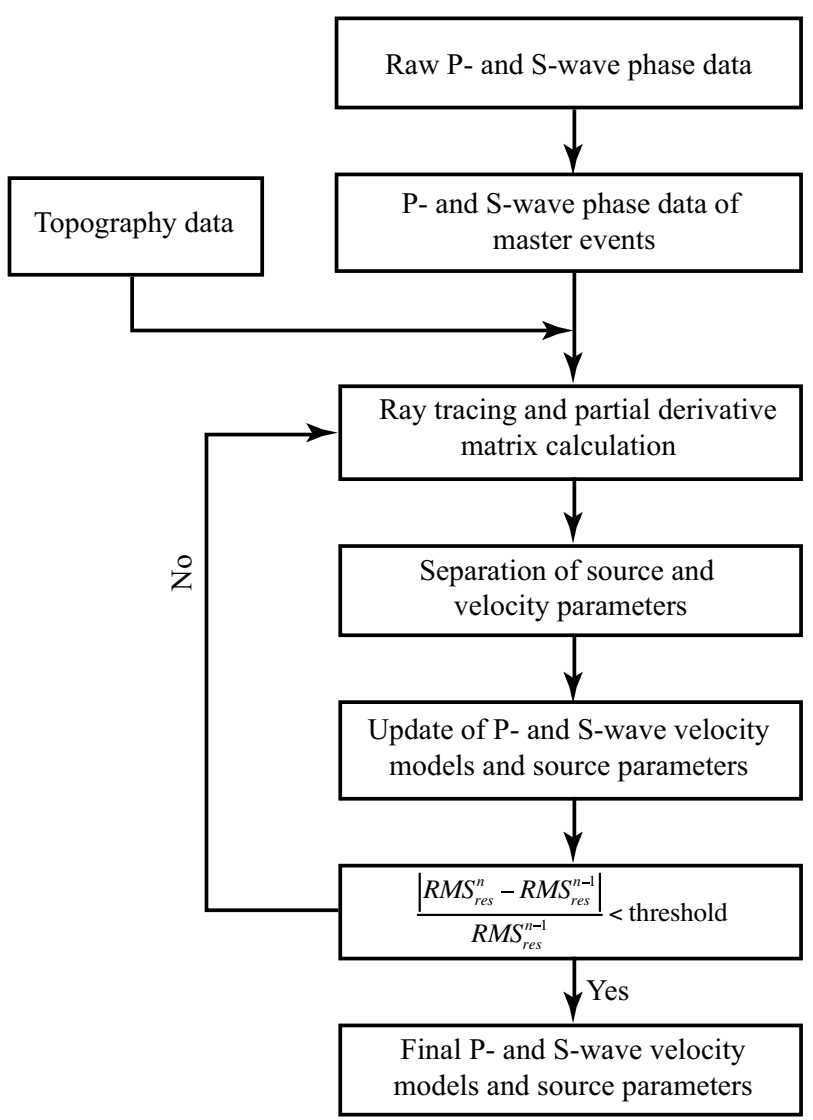

Figure 1. A work flowchart of our local earthquake tomography with full topography algorithm presented in this study. 
a)

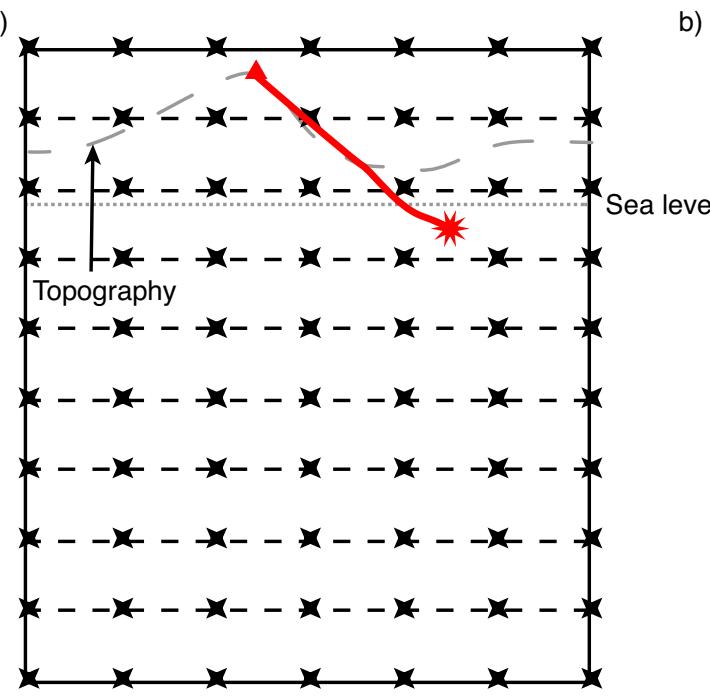

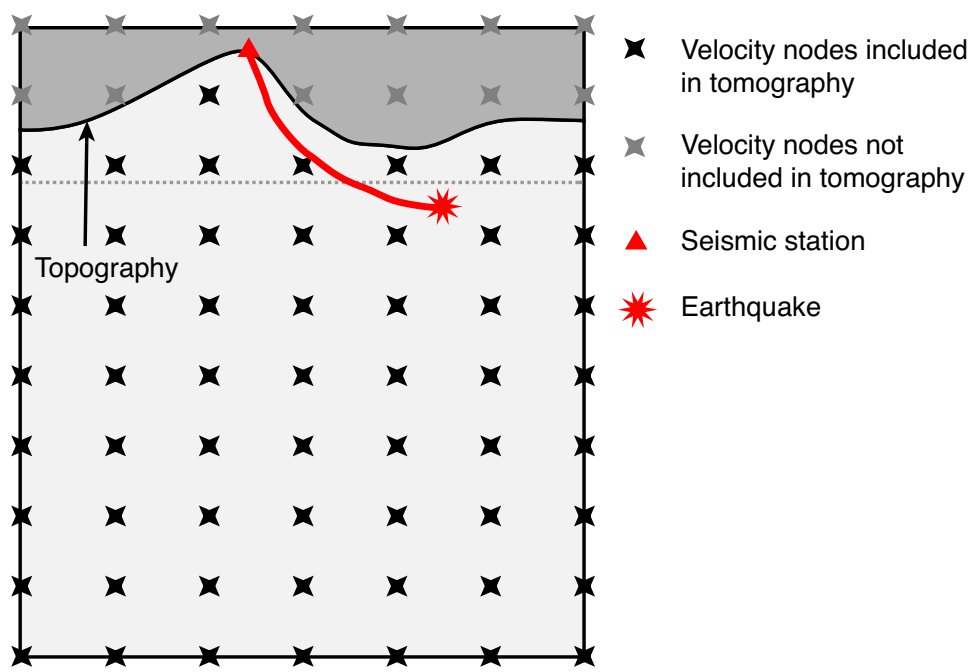

Figure 2. Schematic illustration of the difference between the traditional LET method (a) and the LETFT method (b). 

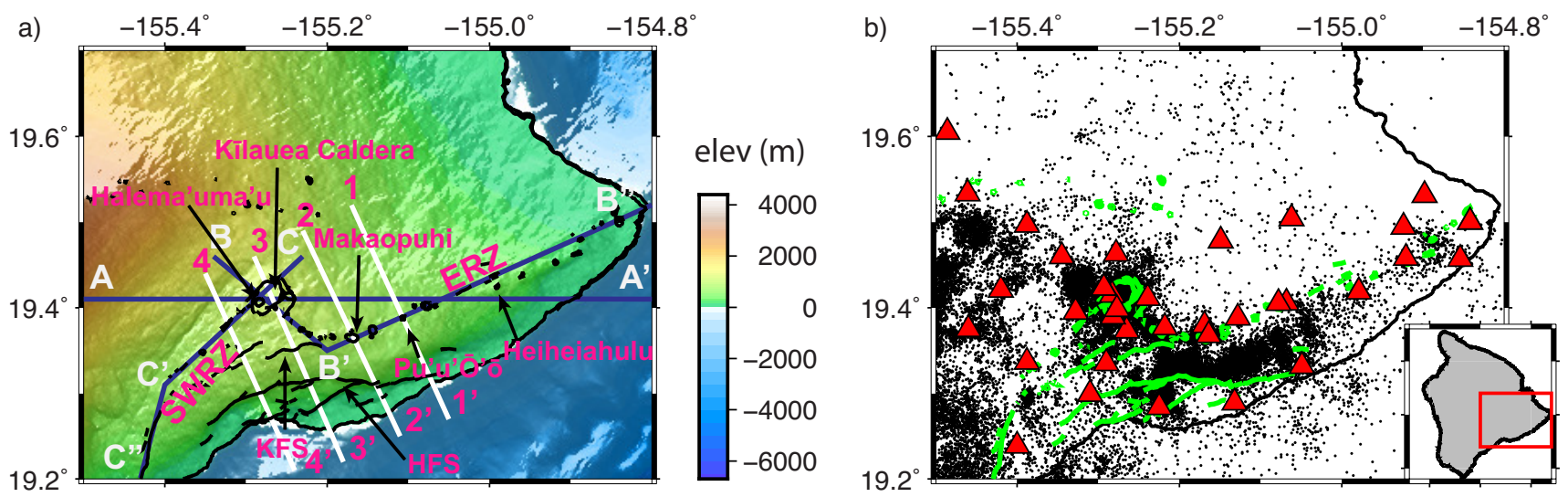

Figure 3. (a) Geological features in our study area, including Kllauea's summit caldera, the East Rift Zone (ERZ), the Southwest Rift Zone (SWRZ), the Hilina Fault System (HFS), and the Koa'e Fault System (KFS). The white and dark blue lines are two groups of the profiles for the cross-sectional views in the following figures. The background is the topography basemap from the Hawaiian multibeam bathymetry synthesis (http://www.soest.hawaii.edu/hmrg/multibeam, last access in August 2015). (b) Seismic events and stations used in this study. Black dots represent earthquakes from 1992 to 2009 recorded by the seismic stations (red triangles) at the Hawaiian Volcano Observatory. Green lines are the surface traces of the major faults and craters. Red box in the inset map shows the location of our study area on the island. 

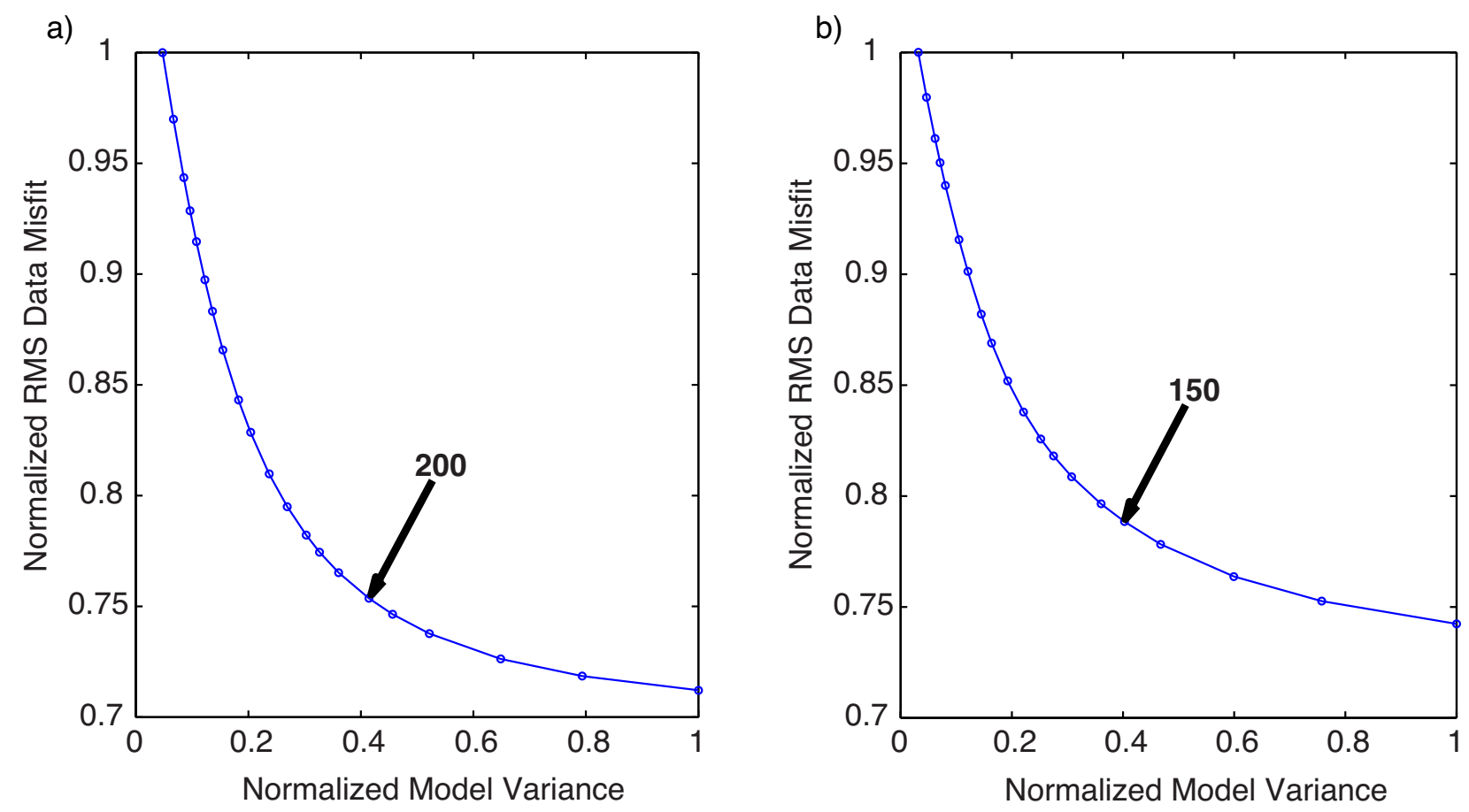

Figure 4. Trade-off curves between data misfit and model variance for P-wave (a) and Swave (b) velocity models. Damping parameters of 200 and 150 are selected for P- and S-models, respectively, in both the synthetic and real data tomography. 
a)

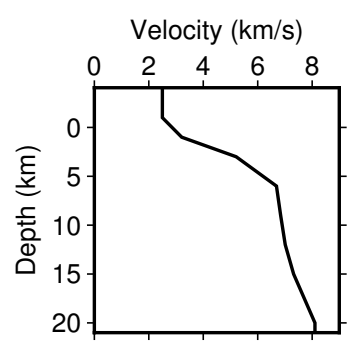

b) $\mathbf{A}$

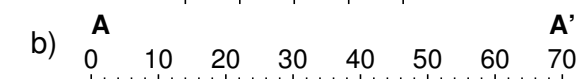

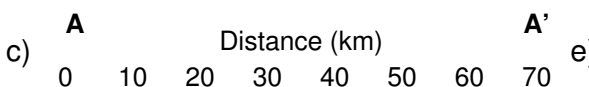

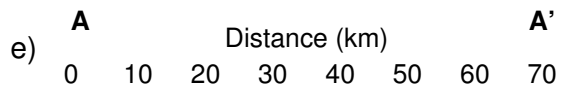
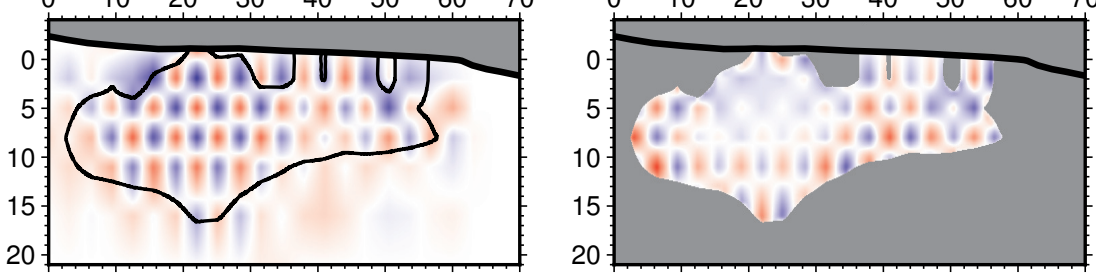

d)

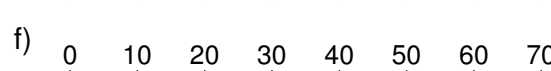

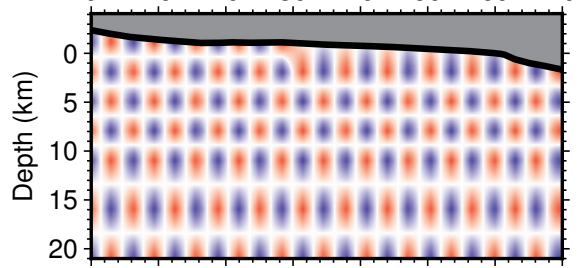
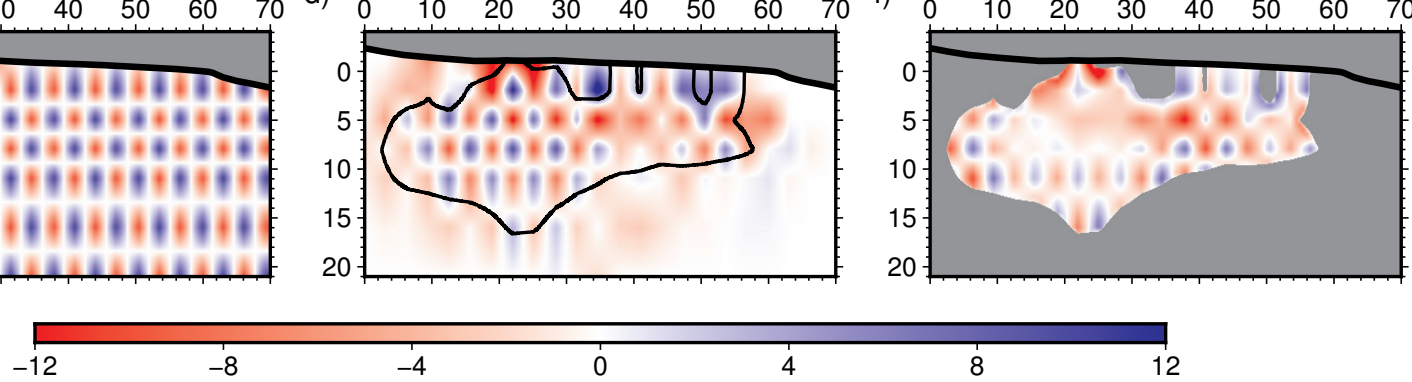

Velocity perturbation (\%)

Figure 5. Synthetic data test comparison of the P-velocity models from the local earthquake tomography with full topography (LETFT) and the traditional local earthquake tomography (LET). (a) 1-D initial P-wave velocity model used in this study. (b) True P-velocity model used in the synthetic data test along profile A-A' in Figure 3a. Thick black curve at top illustrates the local topography. (c, d) Inverted P-velocity model from the LETFT and the LET, respectively. Black contours enclose the area with the diagonal element of the resolution matrix greater than 0.4, which are considered well-resolved. (e, f) P-velocity model difference for the well-resolved area of the LETFE and the LET model relative to the true model, respectively. 


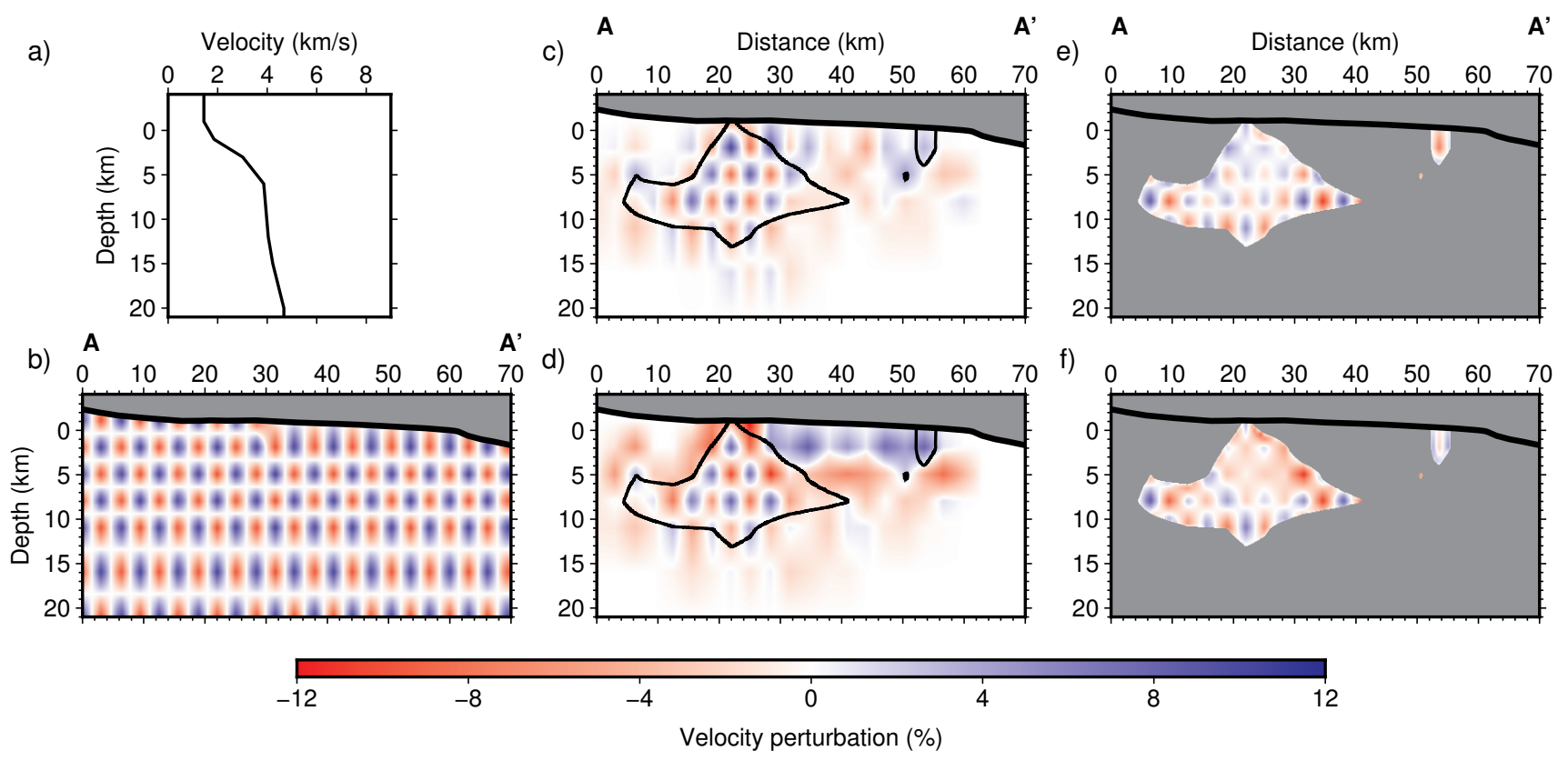

Figure 6. Synthetic data test comparison of the S-velocity models from the local earthquake tomography with full topography (LETFT) and the traditional local earthquake tomography (LET). (a) 1-D initial S-wave velocity model used in this study. (b) True S-velocity model used in the synthetic data test along profile A-A' in Figure 3a. Thick black curve at top illustrates the local topography. (c, d) Inverted S-velocity model from the LETFT and the LET, respectively. Black contours enclose the area with the diagonal element of the resolution matrix greater than 0.4, which are considered well-resolved. (e, f) S-velocity model difference for the well-resolved area of the LETFE and the LET model relative to the true model, respectively. 
Table 1. Tomographic inversion result comparison between the LETFT and traditional LET methods for the synthetic data test. Definitions of the errors are explained in the main text. "Shallow" refers to above $5 \mathrm{~km}$ depth. RMS is short for Root Mean Square.

\begin{tabular}{lcc}
\hline & LETFT & LET \\
\hline Location error in longitude $(\mathrm{m})$ & 47.5 & 101.7 \\
Location error in latitude $(\mathrm{m})$ & 59.2 & 108.0 \\
Location error in depth $(\mathrm{m})$ & 72.0 & 152.3 \\
Origin time error $(\mathrm{s})$ & 0.018 & 0.050 \\
P velocity model error $(\mathrm{km} / \mathrm{s})$ & 0.15 & 0.20 \\
Shallow P velocity error $(\mathrm{km} / \mathrm{s})$ & 0.09 & 0.20 \\
S velocity model error $(\mathrm{km} / \mathrm{s})$ & 0.12 & 0.21 \\
Shallow S velocity error $(\mathrm{km} / \mathrm{s})$ & 0.09 & 0.21 \\
RMS of residual $(\mathrm{s})$ & 0.012 & 0.016 \\
\hline
\end{tabular}




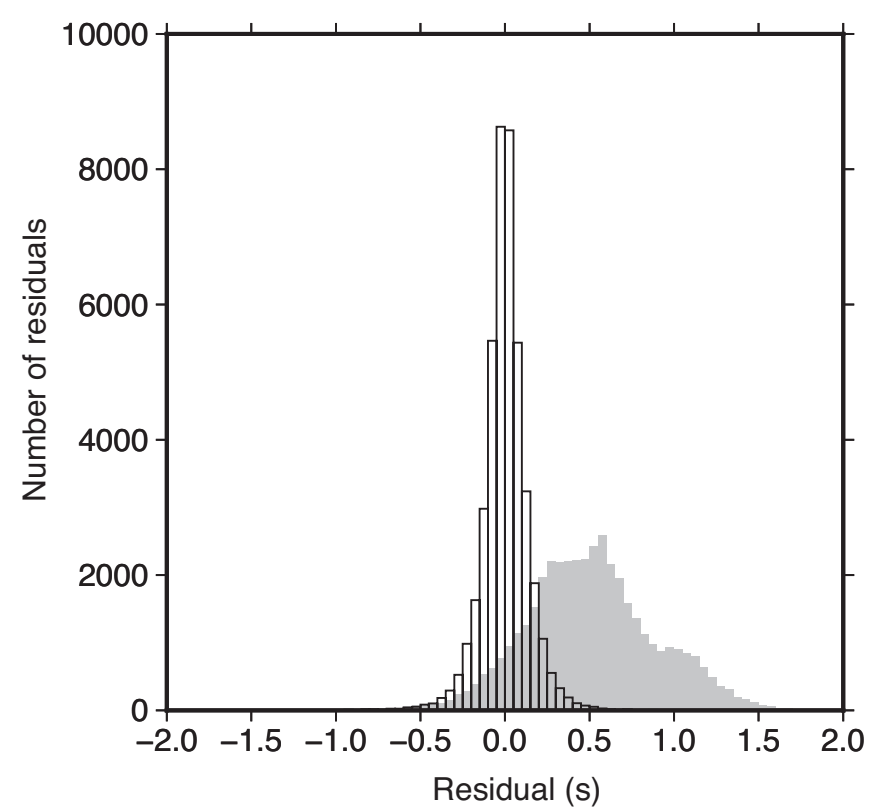

Figure 7. Histograms of the real data travel time residuals from the initial 1-D velocity model (gray) and the inverted 3-D velocity model (black and white). The root-mean-square residual is reduced from 0.65 to $0.14 \mathrm{~s}$. 

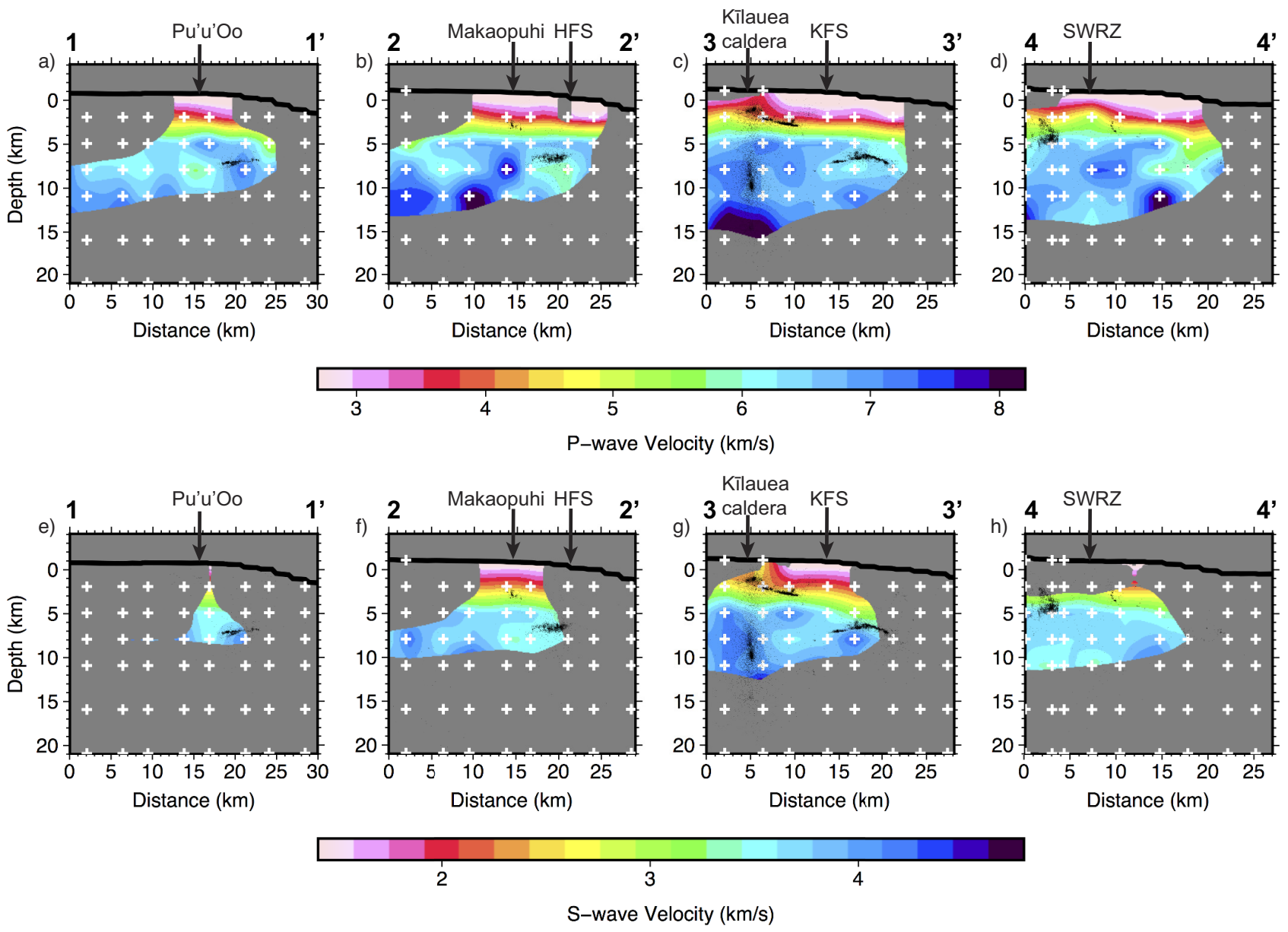

Figure 8. Cross-sectional views of the inverted P-wave velocity model (a-d) and S-wave velocity model (e-h) along profiles 1-1', 2-2', 3-3' and 4-4' in Figure 3a. White crosses are the inversion nodes within $\pm 1.5 \mathrm{~km}$ distance of the profile line projected onto the vertical profiles. Black dots are the waveform cross-correlation relocated seismicity by Lin et al. [2014]. 

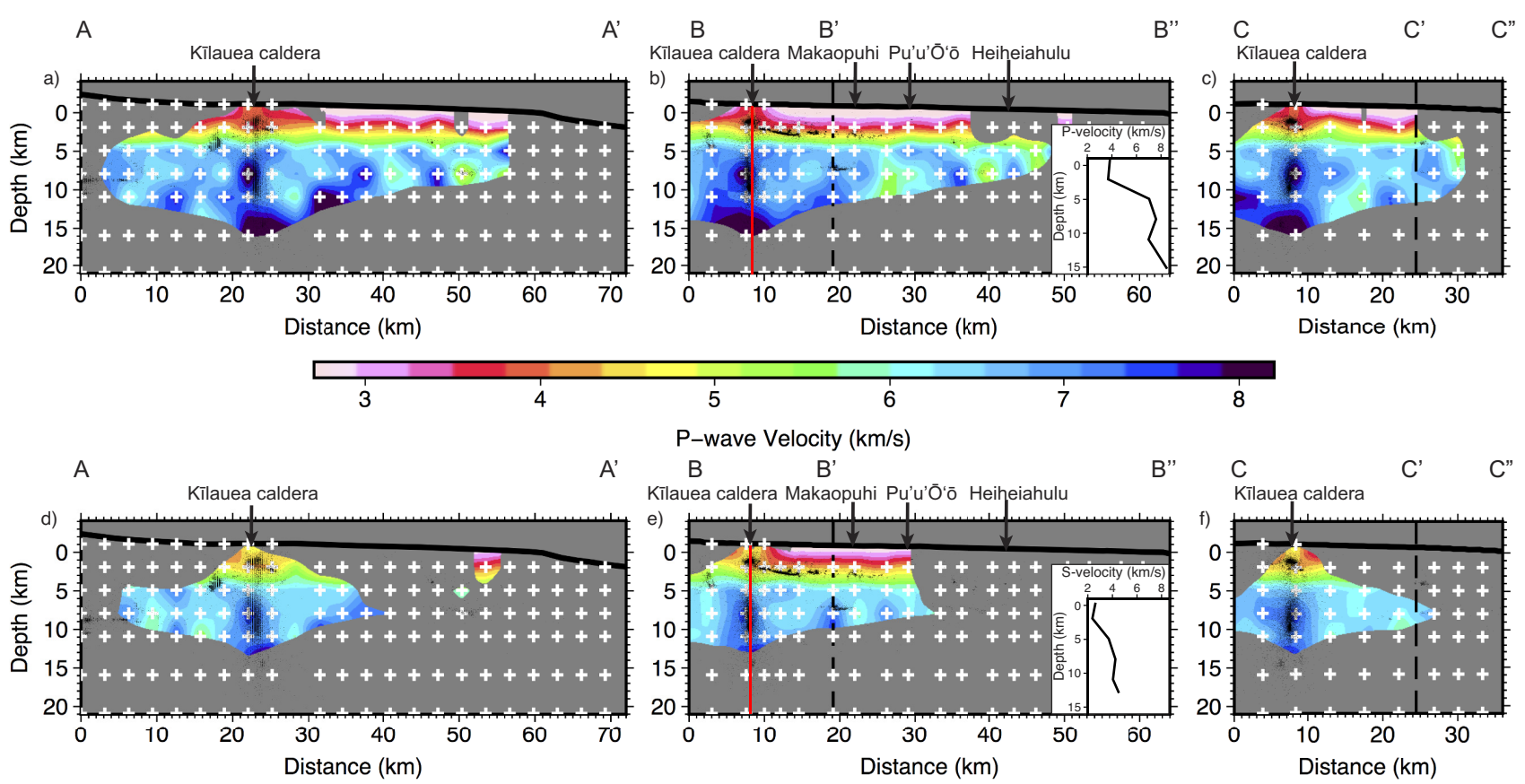

$A^{\prime}$

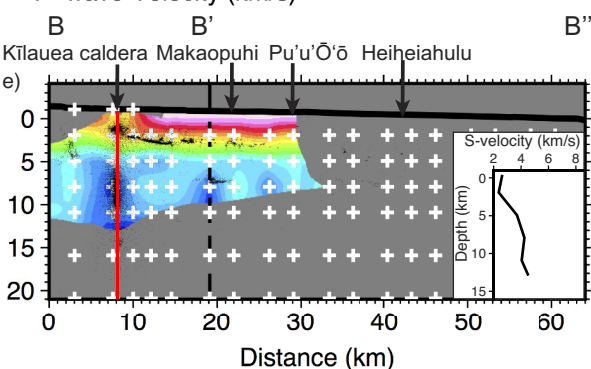

B"

8

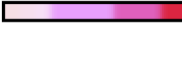

2

S-wave Velocity $(\mathrm{km} / \mathrm{s})$

Figure 9. Cross-sectional views of the inverted P- (a-c) and S-wave velocity model (d-f) along profiles A-A', B-B'-B", and C-C'-C"' in Figure 3a. The insets in (b) and (e) are the layer-average P- and S-wave velocity values in the well resolved portion along the red vertical line beneath Kilauea caldera. White crosses are the inversion nodes projected onto the vertical profiles. Black dots are the waveform cross-correlation relocated seismicity by Lin et al. [2014]. 

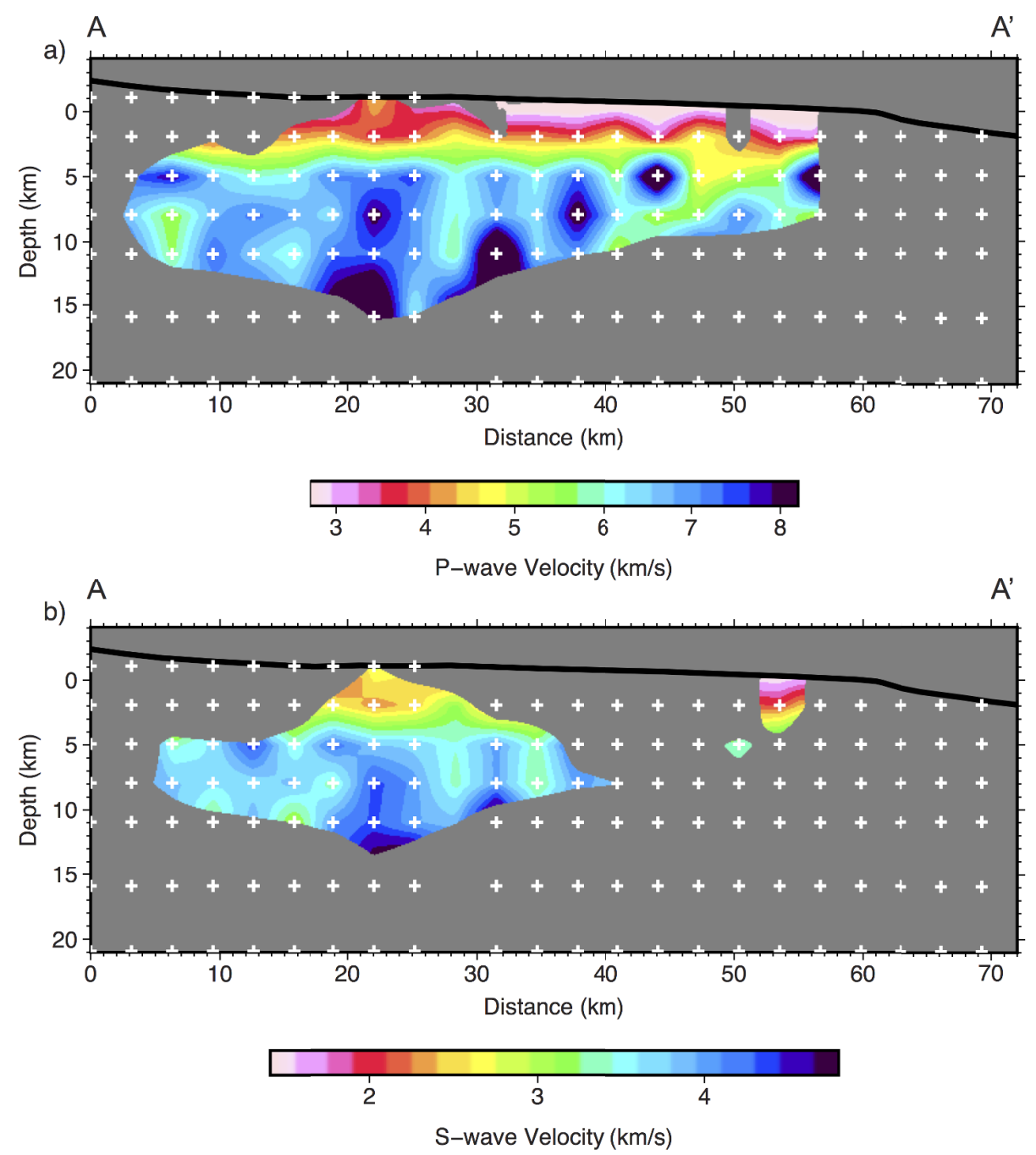

Figure 10. Velocity models of the robustness test along profile A-A' in Figure 3a. (a) and (b) are the inverted P- and S-wave velocity models from the perturbed data by Gaussian distributed noise. 

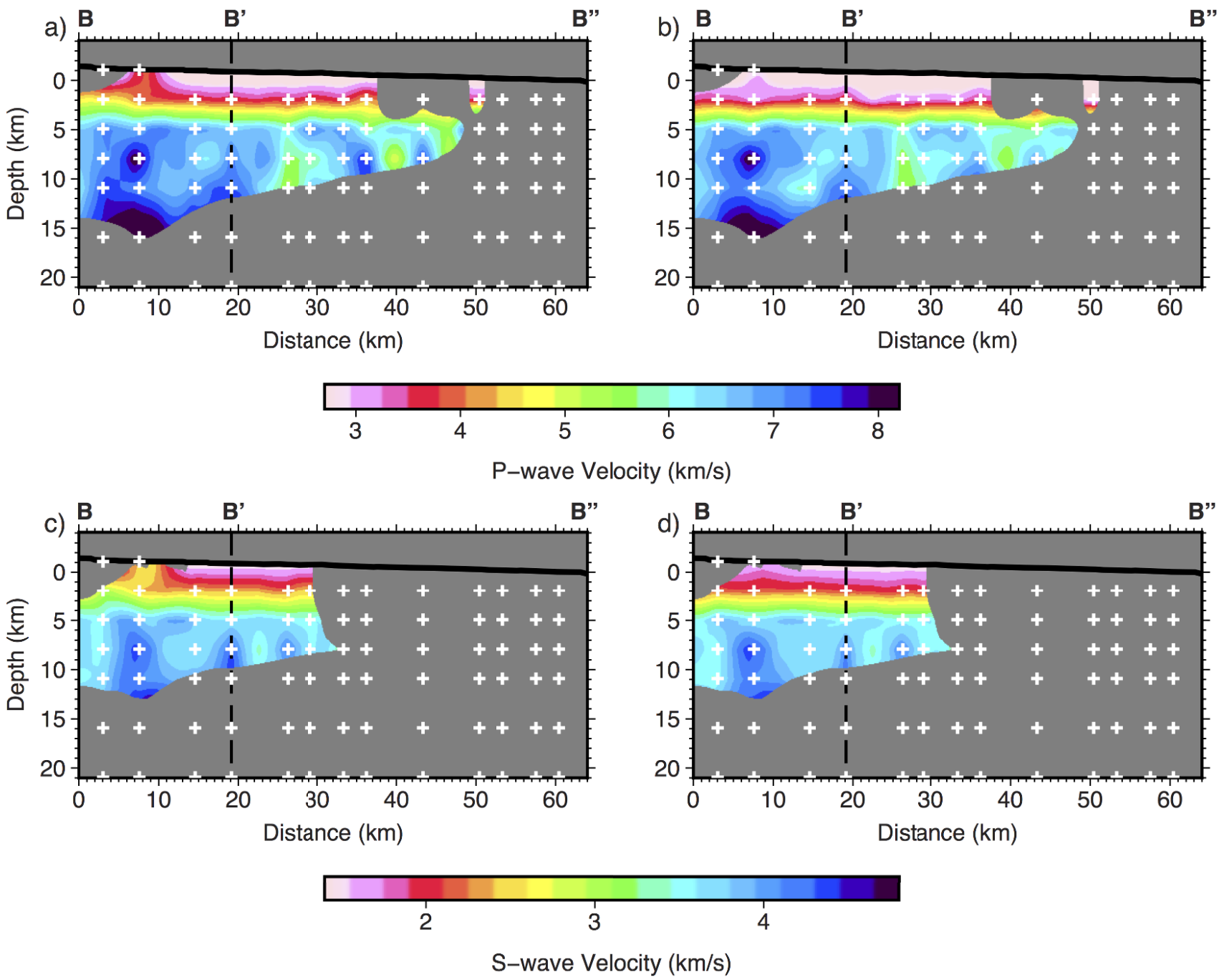

Figure 11. Velocity model comparison based on the real data from the local earthquake tomography with full topography $(\mathrm{a}, \mathrm{c})$ and the traditional local earthquake tomography $(\mathrm{b}, \mathrm{d})$ along profile B-B'-B" in Figure 3a. 